DE

M E D I C I N A

T R O P I C A L

$\mathrm{DE}$

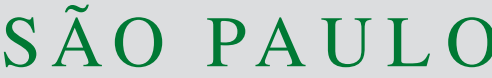

JOURNAL OF THE SÃO PAULO INSTITUTE OF TROPICAL MEDICINE

(1) Universidade Federal do Maranhão, Programa de Pós-Gaduação em Saúde do Adulto e da Criança, São Luís, Maranhão, Brazil

(2) Universidade Federal do Maranhão, Programa de Pós-Graduação em Enfermagem, São Luís, Maranhão, Brazil

(3) Universidade Federal do Maranhão, Faculdade de Medicina, São Luís, Maranhão, Brazil

Correspondence to: Maria do Desterro Soares Brandão Nascimento Universidade Federal do Maranhão, Departamento de Patologia, Núcleo de Imunologia Básica e Aplicada, Av. dos Portugueses, 1966, Prédio do CCBS, Bloco 3, Sala 3A, CEP 65080-040, São Luís, MA, Brazil

Tel: +55983272 8535

Fax: +55983272 8535

E-mail: cnsd_ma@uol.com.br

Received: 20 July 2016

Accepted: 22 February 2017

\section{Knowledge and perceptions on toxoplasmosis among pregnant women and nurses who provide prenatal in primary care}

\author{
Jayra Adrianna da Silva Sousa ${ }^{1}$, Rita da Graça Carvalhal Frazão Corrêa', \\ Dorlene Maria Cardoso de Aquino ${ }^{2}$, Nair Portela Silva Coutinho ${ }^{2}$, Marcos Antonio \\ Custódio Neto da Silva ${ }^{3}$, Maria do Desterro Soares Brandão Nascimento ${ }^{1}$
}

\section{ABSTRACT}

Background: Toxoplasmosis is an infection that affects almost a third of the world population. In adults, it is often asymptomatic, although having important manifestation in children- infected by placental transmission. The prenatal is an important moment, requiring actions in women's care during pregnancy, in order to prevent diseases that could compromise the mother and the child's life. Methods: This is a descriptive study of qualitative approach aimed to understand the perception of nurses and pregnant women about toxoplasmosis during primary - prenatal care. The study was conducted in five selected primary health care units, in the municipality of São Luis - MA. The sample consisted of 15 nurses working in nursing consultation and 15 pregnant women attended in prenatal care. For data collection, a semi-structured questionnaire and an interview guide covering issues related to knowledge and conduct on toxoplasmosis were used. For analysis, the content analysis technique was used. Results: The answers were transcribed, organized and grouped thematically, where the following categories emerged: knowledge about examination requests; knowledge about toxoplasmosis; guidance during prenatal consultation; knowledge of nurses about the avidity test; procedures and guidelines on reagent cases. Pregnant women showed unawareness about toxoplasmosis and its effects. Nurses, although having basic knowledge about the subject, showed little applicability regarding pregnant women's guidance. Conclusion: The nurse plays an important role in educational activities regarding pregnant women, contributing to the quality of prenatal care. Pregnant women were shown to have some knowledge about toxoplasmosis, although they said they did not have assurance about prevention.

KEYWORDS: Toxoplasmosis. Pregnant women. Nurse. Primary care.

\section{BACKGROUND}

Pregnancy is an important event in the life of any woman and it is surrounded by many anatomical and physiological changes, besides being also influenced by alterations and pathologies that may be significant on driving a healthy pregnancy, causing risks to the mother and/or child. Prenatal care should be performed as early as possible, from the moment the pregnancy is diagnosed, in order to prevent risks to the life of the pregnant woman and the fetus ${ }^{1}$.

Toxoplasmosis is caused by an obligate intracellular protozoan, Toxoplasma gondii (T. gondii), which infects nearly a third of the population worldwide. The definitive hosts are cats and other felines. Intermediate hosts are all warm-blooded animals including most livestock, humans and members of the Feliade family ${ }^{2,3}$. The infection can be acquired through oocysts from cat feces which may be present 
in soil, water or food; Eating raw meat or poorly cooked meat containing bradyzoites; Toxoplasma gondii may be transmitted vertically by tachyzoites that are passed to the foetus via the placenta ${ }^{4,5}$.

In face of these factors, the epidemiological data shows the importance of discussing this subject. It is estimated that $40 \%$ to $80 \%$ of the adult population has already been infected by $T$. gondii. The incidence of acute toxoplasmosis is $0.2 \%$ to $1 \%^{6}$. When it occurs during pregnancy the risk of fetal infection is greater than $40 \%$, which can lead to several complications ${ }^{6,7}$. Approximately $85 \%$ of infants with congenital toxoplasmosis show no evident clinical signs at birth?

With a more detailed assessment, they may show changes such as intrauterine growth restriction, prematurity, cerebrospinal fluid abnormalities and retinochoroiditis scarring ${ }^{8,9}$. Toxoplasmosis is known as a major cause of perinatal morbidity. Most infected pregnant women are asymptomatic. Acute infection in pregnancy can lead to fetal infection and subsequent fetal loss or the birth of a manifestly or latently infected child ${ }^{10}$. Considering that health education is a strategy to prevent and reduce the risk of toxoplasmosis exposure in pregnant women, it is critical that health-care actions in primary care develop interventions to assist pregnant women. Nurses are responsible for carrying out educational activities for women with low-risk pregnancy and their families during prenatal consultations ${ }^{11-13}$. The paramount importance of the health-care professional's performance in all pregnancy processes is noted, including detection, guidance, and action to be taken by the diagnosis of toxoplasmosis in the course of a pregnancy.

The incidence of toxoplasmosis and the high prevalence in pregnant women has sparked interest in this study; and in this context, our starting point was the following question: what are the perceptions of nurses and pregnant women about toxoplasmosis during their prenatal primary care?

\section{METHODS}

\section{Study design}

The chosen method was a descriptive study using a qualitative approach to obtain subjective information that cannot be quantified. Our qualitative research sought to understand the meaning attributed by the participants to the facts, relationships, practices, and social phenomena during prenatal primary care ${ }^{14}$.

\section{Area of study}

A study conducted in-five of the 104 Health Strategy
Teams of active family in São Luis, State of Maranhão, Brazil. São Luis is located at a latitude of 2०31'47" S and a longitude of $44^{\circ} 18^{\prime} 10^{\prime \prime} \mathrm{W}$, and it is $24 \mathrm{~m}$ above sea level. This city covers an area of approximately $830 \mathrm{~km}^{2}$ and has a population of $1,017,772$ inhabitants ${ }^{15}$.

The units were randomly chosen: San Francisco Health Center, Djalma Marques Health Center, João Paulo Health Center, Turu Health Center and São Raimundo Health Center.

\section{Study population}

The study population included 30 participants: 15 nurses working in prenatal nursing consultation in low-risk pregnancies and 15 pregnant women who attended primary care in the municipality of São Luis, Maranhão, Brazil. The sample was defined by saturation criteria during data collection; interviews were suspended when information provided was repetitious, adding no new elements to the analysis. This condition is sample sufficiency criteria in qualitative research ${ }^{16}$.

\section{Data collection}

Data collection was performed in four randomly chosen Family Health Strategy Units. The interviews were conducted from September to November, 2014. For collection, a questionnaire was used to identify the participants and an interview guide was applied for nurses and pregnant women, which was related to knowledge and behaviors associated with toxoplasmosis. Interviews were conducted in the prenatal clinic according to the availability and convenience of nurses and pregnant women after prior appointment. Pregnant women were approached while waiting to perform their prenatal consultation and nurses were approached after the end of attendance. The interviews were -made by the same person. All participants agreed to participate in the study and there was no loss to follow-up during this study.

\section{Data analysis}

The thematic analysis is the way that best suits the qualitative health research. Thus, in this study thematic analysis will be used. The operationalization of the thematic analysis unfolds in three phases: the first phase, which will be carried out using the transcripts of the interviews and the organization of all research material, including structured questionnaires and reports. The second phase will explore the material collected in the field by means of floating and exhaustive reading of these material. The third and final phase will seek- to understand the reports ${ }^{14}$. 


\section{Ethical aspects}

Participants authorized the recording of the interview and signed an informed consent form. The study met the requirements of CNS resolution $\mathrm{N}^{\circ} 466 / 12$ and was approved by the Research Ethics Committee of the University Hospital of the Federal University of Maranhão, São Luís, Maranhão, Brazil, process number $\mathrm{N}^{\circ}$ 784.303.

\section{RESULTS AND DISCUSSION}

Study participants consisted of 15 nurses working in primary care and 15 pregnant women who underwent prenatal low-risk consultation in primary care units in São Luis, MA.

The women participating in the study were aged between 16 and 35 years old. Among these, 10 began prenatal care in the first trimester, three in the second trimester and two in the third trimester. Nine women were in their first pregnancy, two were in their second and four were multiparous. Among nurses who participated in the study, 11 were women and four were men. They aged between 28 and 45 years old. Regarding the training time, the nurses had between 5-20 years' experience after graduation. Of these nurses, eight had a specialization in Family Health Strategy or Primary Care, two had a master's degree in Collective Health and five were recent graduates.

The answers were transcribed, organized and grouped thematically, where the following categories emerged: K-knowledge about examination requests; K-knowledge about toxoplasmosis; guidance during prenatal consultation; knowledge of nurses about the avidity test; conduct and guidelines on reagent cases. Participants were called by interview order to preserve identity.

\section{Knowledge about examination requests}

All pregnant women said they did not know what examinations were requested during the first prenatal consultation. However, they claimed to have had several examinations performed and have received the results. The reception of and humanized care given to pregnant women is the best way to ensure adherence to care and guidance given by the health-care professional.

Patients should be confident in the interventions of their nurses to maintain the quality of their follow-up - in health care.

“....Blood, feces and urine examinations. Yes... blood type. Yeah... tetanus examinations, if I'm not mistaken. And others I do not remember. There were several examinations." (G6)
"All the examinations that they asked for... blood, HIV, hepatitis. I did them all." (G2)

"I know... No, I do not know. But I did them all. CBC, I think I did all other examinations. I just do not remember them." (G1)

Early diagnosis, i.e., the higher the patient's age and the sooner they started prenatal care is very important. This shows the importance of prenatal care to the health of both woman and fetus because it refers to a set of clinical and educational procedures aimed to monitor pregnancy development and promote the health of the mother and child ${ }^{17,18}$.

According to Breganó et al. ${ }^{19}$, it is important for pregnant women to undergo serological tests of anti- $T$. gondiispecific antibodies in the first prenatal consultation. If the pregnant woman does not have these antibodies, besides repeating serology in the second and third trimesters of pregnancy, she should receive guidance on preventive measures. There is sufficient evidence to support the protective effect of quality prenatal care on the health of the mother and of the newborn, which contributes to reduce the incidence of maternal mortality, low birth weight and perinatal mortality ${ }^{20}$.

The need to perform prenatal care as soon as possible and right after the diagnosis of pregnancy should be noted, to prevent any eventualities that may risk the life of the pregnant woman and her child, and, if necessary, to plan for the appropriate interventions (preventive or therapeutic) throughout pregnancy.

Nurses said they knew the examination and that -requested it in the first prenatal visit. Moreover, the importance of nursing consultation on early diagnosis and prompt measures and implementation of the assistance and provide guidance and referral to specialized treatment, as well as the case.

"I ask for all examinations, even though some of the patients will not get all the examinations done because there are some examinations that are only offered in private health, but many patients make them at first, but if it does not show something, they do not want to repeat it at the end of pregnancy." (E7)

“...Blood typing, blood glucose, blood count, urinalysis, serology for rubella, toxoplasmosis, cytomegalovirus, and $P C C U$, in addition to ultrasound" (E1)

"I know them all... and I ask for all of them right at the first visit, because what is wrong and can be treated is treated... but for what is not treatable... the patient goes to the doctor." (E3)

The early beginning of prenatal care and toxoplasmosis screening is essential for success of serological evaluation. It is also necessary to repeat the examination in susceptible 
pregnant women to identify any seroconversion and to prevent infection transmission to the fetus ${ }^{20}$. The risk of maternal-fetal transmission is around $40 \%$ and increases with advancing pregnancy; however, the degree of commitment of the concept is higher at the beginning of gestation when clinical implications are extremely serious, such as neurological and ocular situations ${ }^{10}$.

\section{Knowledge about toxoplasmosis}

Pregnant women were surprised to be asked about what they knew on toxoplasmosis.

Some reported to have received some information, although details were not explained, which demonstrates the need for more educational and informative interventions on toxoplasmosis not only for pregnant women, but also for the community so that the population can take preventive measures by adopting new habits.

"I think so... I made up an examination with this name. The nurse just said I - did not have any problems. I do not know what this disease is." (G12)

"No, toxo... what?! Never heard of it." (G3)

"I think so... let me see!... It is something that is caught from cats, right?! Cat poop, isn't it?!" (G4)

The orientation of pregnant women on methods of preventing $T$. gondii transmission during pregnancy can significantly reduce the acquisition of the infection during pregnancy ${ }^{21}$. Nurses should guide pregnant women about the importance of good prenatal health care because it enables the avoidance of several diseases, toxoplasmosis among them, that can cause fetal death, serious neurological problems, abortion, mental retardation and blindness ${ }^{21}$.

Nurses have demonstrated some knowledge on toxoplasmosis. The information provided by the health care professionals is an educational and preventive intervention for many diseases, but it needs to be passed more dynamically considering the cultural conditions and education level of the population in the area where he or she operates.

"Well, I know that it is transmitted by this protozoan, T. gondii. It can bring serious consequences for the fetus, such as vision or hearing loss." (E4)

"It is a disease that is transmitted through cat feces, which in pregnant women causes problems for the fetus, such as hydrocephaly, low weight and abortion." (E1)

"The knowledge I have about toxoplasmosis. It is an infection that affects many pregnant women. It has a very strong involvement to the pregnant woman and the baby. It has a number of complications to the baby, such as malformation. Thus, screening is very important in prenatal care to avoid these complications." (E2)
"That's a disease transmitted by... I think it is a protozoan that is transmitted through poorly sanitized meat. It is present in animal feces, like cats feces, especially newborn cats, so I already had information. It seems that adult cats do not transmit it." (E5)

According to Amendoeira and Camillo-Coura ${ }^{22}$ T. gondii infection can cause spontaneous abortion, premature birth, stillbirth or severe sequelae in the fetus (e.g., the classic triad of Sabin) if the infection is acquired during pregnancy, especially during the first two trimesters. According to Carrellos et al. ${ }^{23}$, the nurse is extremely important in prenatal consultations. Investments need to be made for a better qualification with effective health care, so that the nurse has the knowledge of the best practices to be passed on to pregnant women. However, it is emphasized that some healthcare professionals do not provide quality care.

In a study performed in Brazil, it was revealed that nurses and doctors had little information about preventive measures of toxoplasmosis and nurses were unaware of information on diagnosis and clinical issues ${ }^{24}$.

\section{Guidance during prenatal consultation}

Pregnant women need to be oriented about all performed examinations (blood count, fasting blood glucose, urinalysis, urine culture, serology for syphilis, hepatitis B, HIV, toxoplasmosis and blood typing), to ensure the maternal-fetal welfare, preventing and diagnosing diseases that affect the fetus and ensure a good prenatal care. The congenital diseases need to be explained to pregnant women. A prenatal nursing care, well supported by consultations, examinations, guidance and periodic educational interventions prevents various diseases and/or complications for the mother and her child.

"I was oriented, but only when the examination results were delivered, because the examination result was reagent, I don't know. Then the nurse explained it to me." (G11)

"No, I was never oriented." (G1)

"I do not know. Can you believe it?! I do not remember. But I think so" (G2)

"No. I was guided only on hepatitis A and B examinations, but -on this one no. Not even when I was pregnant with my other boy." (G6)

Breganó et al. ${ }^{19}$ found that, among the women interviewed, a large proportion (60\%) reported not having received any guidance on the risks of contamination by T. gondii by health-care professionals providing prenatal care. The interaction between the pregnant woman and health-care professionals is very important for the management of maternal and congenital toxoplasmosis. 
Gomes ${ }^{25}$ stated that the low frequency of pregnant women who underwent an additional $\operatorname{IgG}$ avidity test might be because of miscommunication among laboratories, the basic healthcare unit/professional and the pregnant woman. Healthcare professionals are responsible for conducting prenatal primary care and accompanying mothers to identify potential risks, guiding the pregnant woman through highrisk prenatal monitoring.

"I usually guide them only if Ig G and IgM were altered. For example, if $\mathrm{IgG}$ is negative, usually I orientate them to avoid contact with cats and raw foods that may be contaminated by cat secretions." (E7)

"Yes. We even make guidelines for the care with food hygiene and the cooking of food, especially if she has the nonreactive lgG. I usually guide them." (E4)

"Yes. The orientation is towards tracking. To take care during the prenatal to avoid this diagnosis in the postpartum, right?! It is also to minimize complications and damage for the baby." (E2)

"When I request the examinations, I already guide on each examination and the importance of toxoplasmosis in pregnancy, because it is a disease that is sometimes asymptomatic. However, pregnancy has repercussions in the fetus, the baby's health. Hence we guide, okay?” (E5)

Among the healthcare professionals in - primary prenatal care, the nurse occupies a prominent position on the team because he or she is a healthcare professional qualified to assist women, with an important role in the educational prevention and health promotion, as well as a humanizing agent ${ }^{20}$.

It is noteworthy that the entire process of tracking, diagnosis (clinically confirmed, but not solely relies on anti-Toxoplasma IgG and IgM antibodies), treatment, and monitoring of the pregnant woman and child should be done with urgency, and should involve not only nurses, but also a multidisciplinary team.

\section{Knowledge of nurses about the avidity test}

The nurses knew the existence of the avidity test, but they did not routinely request- the test and had difficulties in interpreting the results.

"There are the IgM and IgG serologies, and I learned that there is a more accurate test, but I do not know how to give this direction. So I submit the patient soon to the doctor." (E13)

"Apart from basic serology, I think there is the PCR and ultrasound, that shows severe cases, but this is a medical conduct." (E 15)

"I ask only for the routine serology, but I know there is the avidity test to finalize the diagnosis. I do not ask for it
... I send them to the maternity ward, so they continue their prenatal care there." (E11)

Treatment should be started as soon as there is suspicion. However, the avidity test should be performed before the treatment intervention. This then can prevent unnecessary wrong diagnosis, medical intervention and follow up.

When the first examination during pregnancy shows a positive result, it is recommended to demonstrate the increase in antibody titers obtained in samples with a minimum interval of 3 weeks.

The avidity test for IgG antibodies may help differentiate recent infections from old ones when performed within the first trimester because the prevalence of high-affinity antibodies reflects an old infection, of over 4 months $^{25}$. The correct interpretation of serological examinations and the early diagnosis of acute maternal infection can be decisive factors in the prevention/treatment of severe cases of congenital toxoplasmosis ${ }^{26}$. Healthcare professionals who provide prenatal care should be properly trained in the clinical, diagnostic and preventive aspects of maternal-fetal transmission disease ${ }^{20}$.

Therefore, the professional responsibility in the diagnosis and monitoring of diseases during prenatal care part of healthcare professionals task but there is an important need to update the knowledge of healthcare professionals about the importance of the avidity test, as well as new tests in the first trimester of pregnancy.

\section{Conduct and guidelines on reagent cases}

As noted in the reports of pregnant women, there is little information about toxoplasmosis and even on other diseases investigated in the first trimester of pregnancy. Without this knowledge, they express curiosity and concern about what to do in case of an IgM positive/reagent result.

"I do not even know what to think or what is this disease. I would ask the nurse to explain it." (G8)

"I think my exam have not showed this disease. I did all the tests and I gave her the results, but she said nothing." (G11)

"I do not know. But I would ask what it was. And what I would do to be able to help if it was positive, right?" (G6)

Upon detection of maternal infection, the maximum risk of early clinical signs is about $10 \%$ at $24-30$ weeks. Many asymptomatic infants show ocular or central nervous system injuries that can be prevented or minimized by early treatment ${ }^{20}$.

It is important to highlight the importance of a healthcare approach through educational interventions on toxoplasmosis during gestation in the detection-prevention process, thus ensuring a healthy pregnancy. It is of 
paramount importance and the responsibility of nurses to orientate safely and give the right guidance to pregnant woman.

"If it was positive, I would guide them. I would communicate it to the unit's professional doctors and refer the patient to them for the proper treatment of toxoplasmosis." (E2)

"In this case, we guide them for medical consultation, to assess, and depending on the trimester, we guide mothers about the risk for their baby's health." (E5)

"Look, until now I have never gotten any positive serology... But if I get one, the conduct here is to refer the patient to the doctor. We can notify her and make referrals to the maternity ward, where the monitoring of pregnant women is done." (E4)

The suspect, confirmed and in-investigation cases should be reported to the local Surveillance Epidemiology Department, where the epidemiological investigation form for toxoplasmosis would be completed and the pregnant women referred to their local prenatal care units for highrisk prenatal care. Susceptible pregnant women should receive special attention with rigorous primary prevention and subsequent serological controls for monitoring until the end of the first year of life of newborns whose maternal blood tests were suggestive of risks to the fetus ${ }^{18}$.

Gomes ${ }^{25}$ highlights the importance of a protocol in the treatment and monitoring of toxoplasmosis. According to Gomes, the existence of a protocol can prevent potential adverse events, unnecessary medications, pregnant women's concerns with the fetus and lack of treatment in case of infection.

\section{Study limitations}

Because it is a qualitative study, it was chosen to identify information without quantification, becoming therefore the identification of participants. The evaluation of sociodemographic data could be important for evaluating the results in relation to knowledge on toxoplasmosis during pregnancy.

\section{CONCLUSIONS}

A well-structured primary prenatal care service should be able to capture the pregnant woman in the community in which she lives as soon as possible, and motivate her to keep her prenatal care regular and constant so that good results can be achieved.

This study evaluated and reflected on nurses' knowledge on toxoplasmosis and the lack of information provided to pregnant women during prenatal primary care. In this sense, the importance of the quality of nursing consultation was highlighted. Besides the request for examinations, educational activities should be mandatory and essential for the prevention of diseases, humanization of care, and health care promotion processes.

Pregnant women were shown to have some knowledge on toxoplasmosis, although they said they did not have assurance about information related to prevention. As for nurses, although referring some knowledge, there was little relationship between knowledge and educational activities that would contribute to prevention and promote health. Pregnant women also mentioned not knowing what tests were requested in the first prenatal consultation. However, they claimed to have undergone several tests and referred to the delivery of results. The humanized care given to pregnant women is the best way to ensure adherence to prenatal care and guidance given by the healthcare professional. Quality monitoring ensures the safety of health-care professionals interventions during prenatal care.

\section{CONFLICT OF INTERESTS}

The authors declare that they have no competing interests in the development of this study.

\section{AUTHORS' CONTRIBUTIONS}

JASS participated in the construction of the project, data collection and preparation of the article. RGCFC participated in the project construction, interpretation and elaboration of the article, besides coordinating and participating in all stages of the study. DMCA, NPSC and MACNS participated in the elaboration of the article. MDSBN participated in the construction of the project and in preparation of the article.

\section{ACKNOWLEDGMENTS}

We thank the patients and nurses in this study, the Foundation for Research and Scientific and Technological Development of the State of Maranhão (FAPEMA), and the - Graduate Program in Adult and Child Health at the Federal University of Maranhão.

\section{FUNDING}

Funding was provided by the Foundation for Research and Scientific and Technological Development of the State of Maranhão (FAPEMA). This study has also received support from the Graduate Program for Adult and Child Health. 


\section{REFERENCES}

1. Brasil. Ministério da Saúde. Secretaria de Atenção a Saúde. Departamento de Ações Programáticas Estratégicas. Gestação de alto risco: manual técnico. $5^{\mathrm{a}}$ ed. .Brasília: Ministério da Saúde; 2010

2. Tenter AM, Heckeroth AR, Weiss LM. Toxoplasma gondii: from animals to humans. Int J Parasitol. 2000;30:1217-58.

3. Brasil. Ministério da Saúde. Secretaria de Atenção a Saúde. Doenças infecciosas e parasitárias: guia de bolso. 7. ed. Brasília: Ministério da Saúde; 2008.

4. Reis MM, Terasso MM, Azevedo PA. Perfil sorológico para toxoplasmose em gestantes de um hospital público de Porto Alegre. Rev Bras Ginecol Obstet. 2006;28:158-64.

5. Miranda MM, Souza LM, Aguiar RA, Corrêa Jr. MD, Maia MM, Borges RS, et al. Rastreamento das infecções perinatais na gravidez: realizar ou não? Femina. 2012;40:13-22.

6. Brasil. Ministério da Saúde. Secretaria de Atenção à Saúde. Departamento de Ações Programáticas e Estratégicas. Atenção à saúde do recém-nascido: guia para os profissionais de saúde. $2^{\mathrm{a}}$ ed. Brasília: Ministério da Saúde; 2011.

7. Montoya JG, Liesenfeld O. Toxoplasmosis. Lancet. 2004;363:1965-76.

8. Melamed J, Eckert GU, Spadoni VS, Lago EG, Uberti F. Ocular manifestations of congenital toxoplasmosis. Eye (Lond) 2010;24:528-34

9. Vutova K, Peicheva Z, Popova A, Markova V, Mincheva N, Todorov T. Congenital toxoplasmosis: eye manifestations in infants and children. Ann Trop Paediatr. 2002;22:213-8.

10. Spalding SM, Amendoeira MR, Ribeiro LC, Silveira C, Garcia AP, Camillo-Coura L. Estudo prospectivo de gestantes e seus bebês com risco de transmissão de toxoplasmose congênita em município do Rio Grande do Sul. Rev Soc Bras Med Trop. 2003;36:483-91.

11. Brasil. Ministério da Saúde. Secretaria de Atenção a Saúde. Departamento de Ações Programáticas Estratégicas. Prénatal e puerpério: atenção qualificada e humanizada. Brasília: Ministério da Saúde; 2006.

12. Bueno WF, Ferreira RG, Silva LB, Klein CH, Amendoeira MR, Neves ES. Difficulties observed in a reference center in the diagnosis and management of pregnant women with toxoplasmosis. Sci Med (Porto Alegre). 2010;20:40-4.

13. Kriebs JM. Infectious diseases in pregnancy: issues of screening, prevention, and treatment. J Perinat Neonatal Nurs. 2008;22:214-20.

14. Minayo MC. O desafio do conhecimento: pesquisa qualitativa em saúde. 12ª ed. São Paulo: Hucitec - Abrasco; 2010.
15. Instituto Brasileiro De Geografia e Estatística. Cidades; 2016. [cited 2016 Oct 02]. Available from: http://www.ibge.g.,ov. br/cidadesat/painel/painel.php?codmun=210300\#/.

16. Silverman D. Interpretação de dados qualitativos. Métodos para analise de entrevistas, textos e interações. $3^{\mathrm{a}}$ ed. Porto Alegre: Artmed; 2009.

17. Villena I, Ancelle T, Delmas C, Garcia P, Brézin AP, Thulliez P, et al. Congenital toxoplasmosis in France in 2007: first results from a national surveillance system. Surveillance and outbreak reports. Eurosurveillance. 2010;15(25).

18. Pawlowski ZS, Gromadecka-Sutkiewicz M, Skommer J, Paul M, Rokossowski H, Suchocka E, et al. Impact of health education on knowledge and preventions behavior for congenital toxoplasmosis: the experience in Poznan, Poland. Health Educ Res. 2001;16:493-502.

19. Mitsuka-Breganó R, Lopes-Mori FM, Navarro IT. Toxoplasmose adquirida na gestação e congênita: vigilância em saúde, diagnóstico, tratamento e condutas. Londrina: EDUEL; 2010.

20. Branco BH, Araújo SM, Falavigna-Guilherme AL. Primary prevention of toxoplasmosis: knowledge and attitudes of health professionals and pregnant women of public service of Maringa, Parana state, Brazil. Sci Med (Porto Alegre). 2012; 22; $185-90$.

21. Higa LT, Araújo SM, Tsuneto L, Castilho-Pelloso M, Garcia JL, Santana RG, et al. A prospective study of Toxoplasma-positive pregnant women in southern Brazil: a health alert. Trans R Soc Trop Med Hyg. 2010;104:400-5.

22. Amendoeira MR, Camillo-Coura LF. Uma breve revisão sobre toxoplasmose na gestação. Sci Med (Porto Alegre). 2010;20:113-9.

23. Carellos EV, Andrade GM, Aguiar RA. Avaliação da aplicação do protocolo de triagem pré-natal para toxoplasmose em Belo Horizonte, Minas Gerais, Brasil: estudo transversal em puérperas de duas maternidades. Cad Saúde Pública. 2008;24:391-401.

24. Contiero-Toninato AP, Cavalli HO, Marchioro AA, Ferreira EC, Caniatti MC, Breganó RM, et al. Toxoplasmosis: an examination of knowledge among health professionals and pregnant women in a municipality of the State of Paraná. Rev Soc Bras Med Trop. 2014;47:198-203.

25. Gomes ML. Enfermagem obstétrica: diretrizes assistenciais. Rio de Janeiro: Centro de Estudos da Faculdade de Enfermagem da Universidade do Estado do Rio de Janeiro; 2010.

26. Sartori AL, Minamisava R, Avelino MM, Martins CA. Triagem pré-natal para toxoplasmose e fatores associados à soropositividade de gestantes em Goiânia, Goiás. Rev Bras Ginecol Obstet. 2011;33:93-8. 